\title{
INTEGRATED APPROACH TO GAS-DYNAMIC DESIGNING OF SUPERSONIC AIR INTAKES OF AIRCRAFT
}

\author{
Aleksey KORNEV (D) ${ }^{1}$, Sergii STETSENKO (D ${ }^{1^{*}}$, Victor YATSENKO (D) ${ }^{1}$, \\ Anatoliy SMOLYAKOV (D) ${ }^{1}$, Dmytro KALINICHENKO (D) ${ }^{2}$ \\ ${ }^{1}$ Inter-branch scientific research institute of problems of physical simulation of Zhukovsky National Aerospace \\ University "Kharkov Aviation Institute" "KhAI" (NII PFM KhAI), Kharkiv, Ukraine \\ 2"“Yuzhnoye" Yangel Design Office" State Enterprise ("“uzhnoye" DO" SE), Dnipro, Ukraine
}

Received 03 June 2019; accepted 03 March 2020

\begin{abstract}
The analytical and experimental studies of the aircraft's supersonic air intakes have been carried out. An integrated approach to the gas-dynamic designing of aircraft's supersonic air intakes that eliminates the scale effect problem of a wind tunnel with a small-sized testing area is proposed. The designing approach accelerates the development process and reduces the resource intensity due to the rational distribution of tasks between numerical and physical experiments. The results of the unique tests of the scaled ramjet's air intake physical model in the supersonic wind tunnel are presented.
\end{abstract}

Keywords: integrated approach, supersonic air intake, scale effect, similarity criteria, numerical experiment, physical experiment.

\section{Introduction}

At present, the world's leading aerospace companies are intensifying their activities on the development of a supersonic multi-purpose aircraft. This motivates the need for new approaches to aerodynamics design and simulation of supersonic aircraft.

When designing ramjet propulsion systems (PS), one of the critical goals is the development of supersonic air intakes and ducts. Designing the PS for supersonic aircraft is a particularly complicated engineering task associated with the design of a highly efficient air intake that supports the PS working processes in the required range of operational flight conditions. Air intake design is usually individual in each case and is also labor-intensive and time-consuming when it comes to creating the air duct geometry.

At present, a typical procedure for the gas-dynamic design of the PS ducting is based on the theory of dimension and similarity and may include the following stages (Karpova \& Meshennikov, 2014; Karpov \& Novogorodtsev, 2014a, 2014b; DTIC, 1991; Holland, 1991; Jirásek, 2007; Davis et al., 2010; Rademakers et al., 2013; Knight, 2003; Akman, 2014; Bedretdinov, 2005):
1. Initial analytical estimation of the air intake parameter and air duct geometry. This will provide the first approximation of the required aerodynamic properties for the aircraft's flight pattern and PS operational conditions.

2. Synthesis of the air duct digital 3D model.

3. Iterative creation of the air intake geometry with the purpose of obtaining the flow morphologies that can provide appropriate functioning of the PS via predictive CFD simulations.

4. Wind tunnel (WT) tests based on the results of CFD simulations and creation of the scaled air intake duct model (this includes scaling flow parameters for the test model).

5. Wind tunnel tests (WTT) of the scaled air intake model.

6. Scaling of the model flow parameters from the model to the full-scale air intake.

7. Digital model (DM) verification of scaled models (such as in Jirásek, 2007; Rademakers et al., 2013; Knight, 2003; Akman, 2014, etc.) and then refinement of the full-scale model geometry.

8. Gas-dynamic tuning of the air intake and PS (Davis et al., 2010; Rademakers et al., 2013; Bedretdinov,

${ }^{*}$ Corresponding author. E-mail: stetsenko.sp@gmail.com 
2005) and then evaluating the conformance of the designed air intake to the imposed requirements.

These stages can be properly implemented only if the large-sized pressurized WTs can be carried out, specifically full-sized test benches, which are unavailable for most researchers. The problems that have arisen in the course of research and development (R\&D) have revealed many functional disadvantages of an atmospheric WT with a small-sized test area. that preclude a reliable determination of parameters of full-scale air intake ducting path based solely on the results of a scaled WTT.

Both CFD and WTT technologies have many disadvantages related to limited WT technical features causing difficulties with aerodynamic design of the PS's air ducts and intakes. These disadvantages are:

1. A priori poor accuracy of analytical and numerical methods that need to be verified by the WTT methods.

2. The increased error of WTT is observed in the region of separated flows (Holland, 1991; Rademakers et al., 2013).

3. High cost of comprehensive studies using CFD or WTT only (Holland, 1991; Jirásek, 2007; Druzhinin et al., 2011).

4. Impossibility of achieving simultaneously the gas-dynamic similarity throughout the scaled air duct model that operates in various velocity ranges.

5. Inability of the scaled modeling of a ramjet.

6. The range of the airflow conditions which are available while WT tests (that is according to International Standard Atmosphere (ISA)), is short and doesn't cover that one needed for simulating of modern supersonic aircraft.

Because of these issues, the development of the design technique for the internal gas-air ducting paths of supersonic aircraft is a pressing scientific and technical challenge.

The purpose of this paper is to present an integrated approach to designing the gas-air ducts of supersonic aircraft's PS using the example of flows in the models of ramjet's supersonic air intake via a rational CFD - WTT combination.

\section{Integrated approach to gas-dynamic design of components of PS of supersonic AC}

The proposed integrated framework is based on the theory of dimension and similarity. However, its direct application for solving the described problem is limited by the physical properties of the experimental equipment. Therefore, a combinatorial approach to the modeling process has been developed. The approach combines in a specific technological sequence mathematical and physical models, which complement each other in functionality and informativeness, with computational and applied research methods based on available design tools as shown at Figure 1. The intensification of the design process is achieved by the redistribution of the emphasis between CFD and WTT, which has been tested on the example of the subsonic aircraft of the integral airframe - PS configuration (Druzhinin et al., 2011; Kornev \& Boychuk, 2017; Kornev et al., 2018). The presented approach is implemented by integrated computer simulation technologies (including applied CAD to create a parametrically controlled 3D geometry) with emphasis on virtual tests in the environment of digital thermo-gas dynamic flow simulations.

\subsection{Special features of WT-tests of the supersonic air intake scaled model}

Any numerical calculation needs to be validated by physical experiments. We have used a supersonic open-loop balloon wind tunnel of the periodically operated type with a closed working section of $0.6 \times 0.6 \mathrm{~m}$ without a thermal vacuum chamber. The Mach number range is $M=0.5 \div 4$.

The technical limitations of the parameter range available for studies in WT are listed below:

1. The parameters of the experimental conditions at the altitude $H=0$ (Table 1 ) (according to the calibration schedules and tables) disagree with those at ISA altitudes. Consequently, the resulting data of WTT in the WT cannot be used to determine the characteristics of a full-scale design object.

2. Due to low density, and, therefore, high kinematic viscosity, the flow in the WT is characterized by low Reynolds numbers. In other words, the flow viscosity similarity is impossible to achieve. Therefore, in scaled supersonic WT tests, only the Mach number similarity in a supersonic part of the air intake can be considered.

3. In order to avoid flow choking of the test chamber channel, the maximum velocity of the flow in WTT is limited by the transverse dimensions of the model. This condition disagrees with the informativeness, finite dimensions, and design features of the measuring device integrated into the air duct. In the example considered in this paper, these points serve as the basis for limiting the maximum speed of the flow to the Mach number $M=3$ and the maximum characteristic size for the internal flow of the air intake to $D=126 \mathrm{~mm}$.

4. Due to the continuity of the flow in the air intake, at supersonic regimes, it is difficult to differentiate the wave component of the drag and establish the area of self-similarity according to the Reynolds number in the subsonic regions of the air duct.

Table 1. Flow parameters in the WT working chamber

\begin{tabular}{|l|l|}
\hline Mach number & 2 \\
\hline Static pressure & $24939.8 \mathrm{~Pa}$ \\
\hline Static temperature & $160 \mathrm{~K}\left(-113^{\circ} \mathrm{C}\right)$ \\
\hline
\end{tabular}




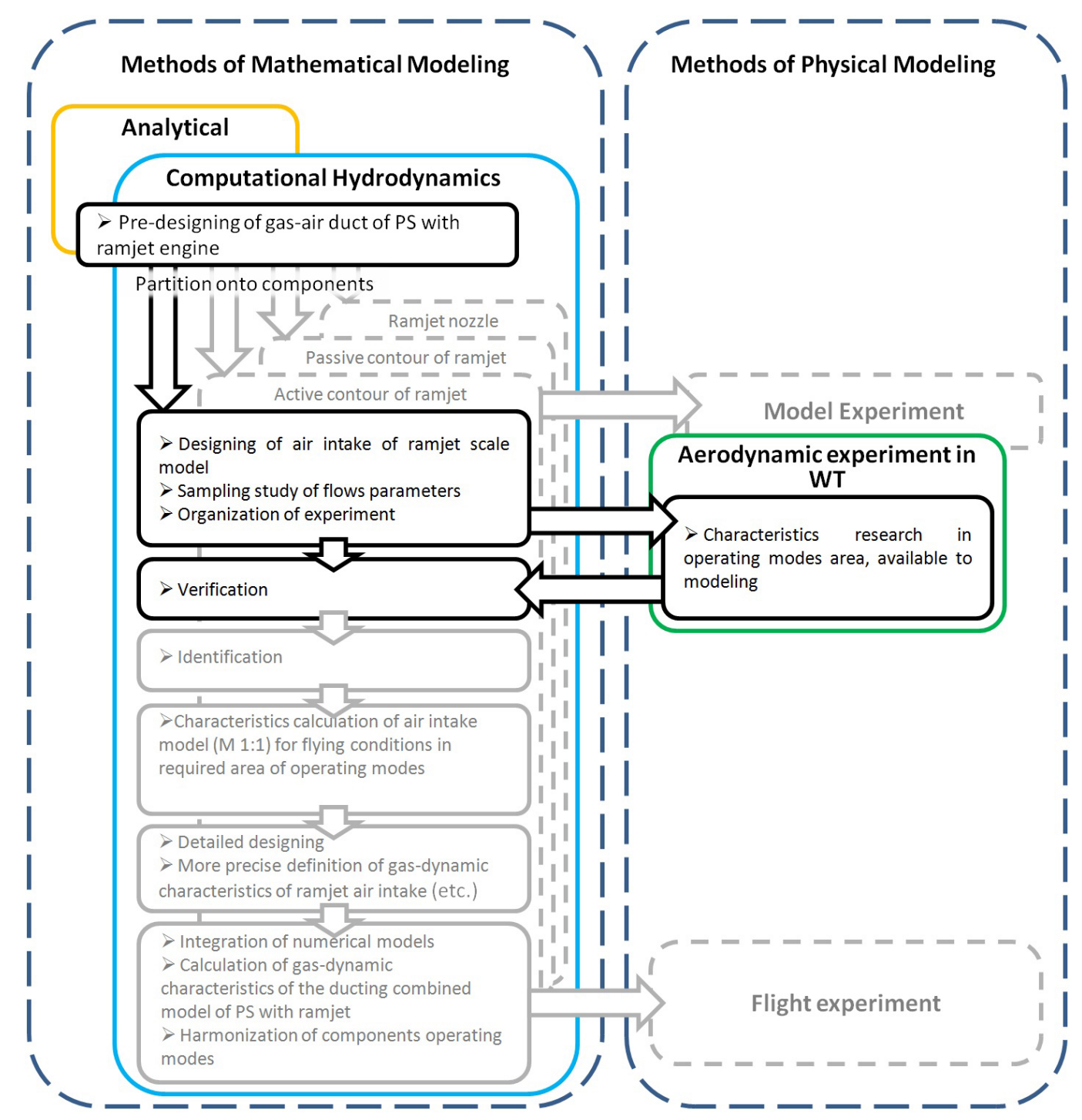

Figure 1. Architecture of the steps for designing sthe supersonic air intake of the ramjet engine (the considered phases are emphasized)

Since the testing area of WT is not equipped with a monitoring system, the tracing of the shock waves in the model air duct is unavailable. This deficiency can be compensated by applied visualization methods duplicated by pressure measurements. The informativeness of the air intake scaled test model is limited by a number of simultaneously surveyed pressure sensors whose are positioned in the areas of interest or critical regions of the air intake duct. The increase in the number of pressure measurements, measured parameters, and control cross-sections leads to a complication of the model and the WT-tests procedure, an increase in the cost of air intake model, and the reduction of the geometric similarity. The latter factor is negatively manifested by a distortion of the flow morphology, blockage of the model channel, and the propagation of disturbances against the flow in the subsonic flow region, introducing measurement errors.

\subsection{The integrated approach distinctive features in the formulation of the CFD tasks for designing a ramjet's supersonic air intake.}

At the initial design stage of the ramjet engine supersonic air intake, the preliminary geometry of the gas-air flow duct is determined via the predictive computational analysis (see Figure 1). The interconnectedness of the working process components in the ramjet engine determines the complexity and resource consumption of the CFD simulation carried out on the ramjet integral model. Designing the air intake as an isolated component of the gas-air duct poses a difficult task of physical verification. As a result, most of the ramjet numerical studies (especially those integrated with the aircraft airframe) have significant technical risks.

However, the classical decomposition principles of applied aerodynamics can be useful if digital submodels 
(DSM) and scaled physical submodels (PSM) of isolated components are used as reference points for autonomous adjustment of the modules and duct components of the ramjet integral model. For this purpose, DSMs separated according to the scheme (see Figure 1) are equipped with the necessary tools (such as measuring system simulators, throttles, etc.). The DSMs serve as the basis for the WT test of the ramjet physical integral model components. For these purposes, small industrial supersonic WTs seem to be quite suitable.

The task of simultaneously meeting the requirements of gas-dynamic similarity with regard to the $M$ and $R e$ numbers is solved by equal scaling of the DSM and PSM of the air intake according to the WTT conditions. It comes down to the identification of the scaled air intake DSM by the WTT results with the aim to achieve the identity to the physical prototype.

To detect and reduce insurmountable a priori errors, various adjustable parameters and options are used to control:

1. Dimension and topology of the computational grid.

2. Assignment of boundary conditions of the "source outflow" type for mass, energy, and momentum to special zones of the air duct Solver type.

3. Selection of the turbulence and viscosity models (including the ability to disable turbulence).

4. Specification of the convergence criteria.

5. Number of iterations.

Numerical methods are used to simulate the scaled WTT. The equivalence of the submodels implies the identity of the geometry and the initial and boundary conditions, as well as a sufficient correlation of the parameters of the simulated and physical flows.

Direct measurements of the total and static pressure at similar points of the internal duct of the DSM and the
PSM of the ramjet's air intake have produced a set of parameters that almost completely describes the air flow in the intake. The key difference from the classical approaches is that the verification of the flow parameters in the supersonic ramjet's air intake does not require recalculation of the similarity criteria. The insufficient informativeness of the measured set of test PSM scalars is supplemented by the visualized compression waves, vector fields, and airflow pathlines in the DSM, thus creating a comprehensive picture of the spatial airflow morphology in the ramjet's air intake. The scaling of the obtained parameters to the full-size DSM and the integral CFD synthesis of the gas-air duct ensure the validity of the results for the subsequent studies of the proper airflow rate tune in the "inlet - ramjet" system for specific flight regimes. That scaling is possible due to the mathematical unambiguity of the physical process description.

\section{Object of Wind Tunnel Test (WTT)}

The tested scaled submodel of the supersonic ramjet air intake consists of four separate modules (see Figures 2-6) that form the air duct. This design allows us to adjust the air duct according to the speed of the incoming air flow. The pneumatic and electrical communications, which are located inside the pylon, run from the measuring unit to the instrumental chamber to arrange static, dynamic pressure and temperature measurements (see Figure 3). The test model is installed on a pylon-base, which serves as a holder. The model is placed inside the flow core, far enough of the working section walls to avoid influence of the boundary layer on the flow parameters (see Figure 7). The model is not equipped with a boundary layer control system.
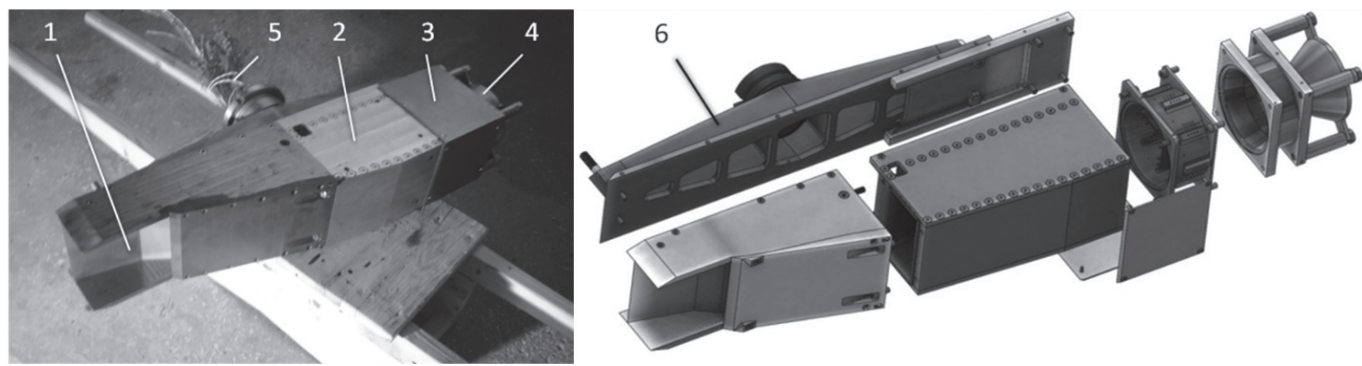

Figure 2. Physical realization and computer image of the PSM: 1 - inlet; 2 - replaceable diffuser;

3 - measuring unit; 4 - throttling device; 5 - pneumatic pipelines; 6 - the base of the model (pylon)

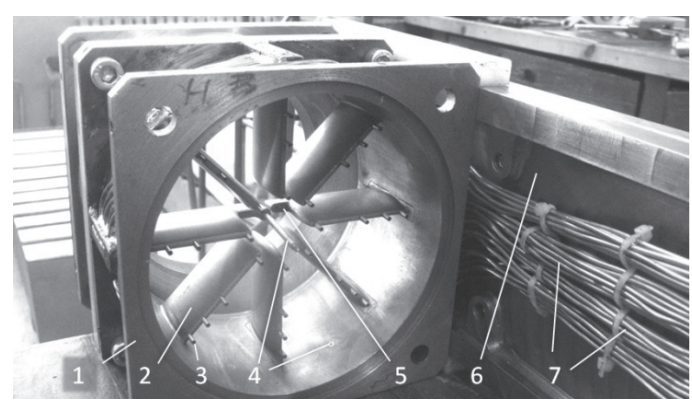

Figure 3. PSM measuring unit. Downstream view: 1 - casing; 2 - support of measuring comb; 3 - total pressure receiver; 4 - static-pressure receiver; 5 - complete braking chamber; 6 - the basis of the model; 7 - pressure pipelines

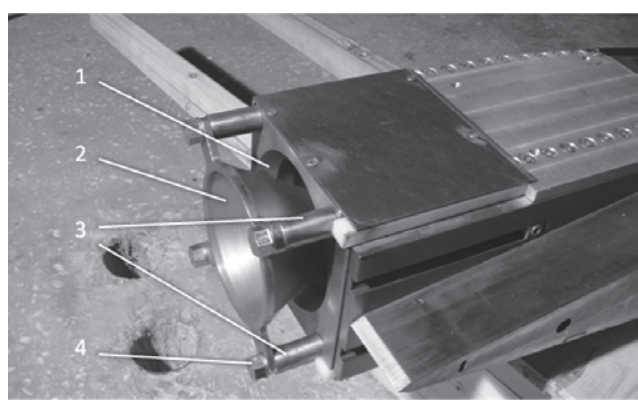

Figure 4. PSM throttling device: 1 - valve seat; 2 - valve; 3 - spacing bush; 4 - fastening screw 


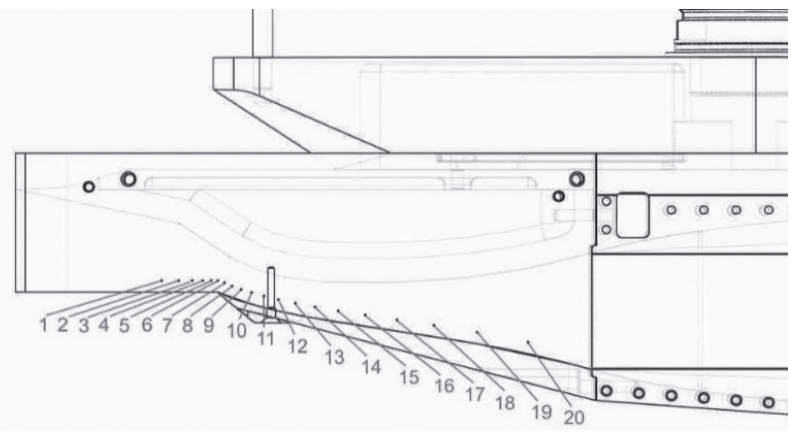

Figure 5. The static pressure taps on the intake diffuser side surface diagram

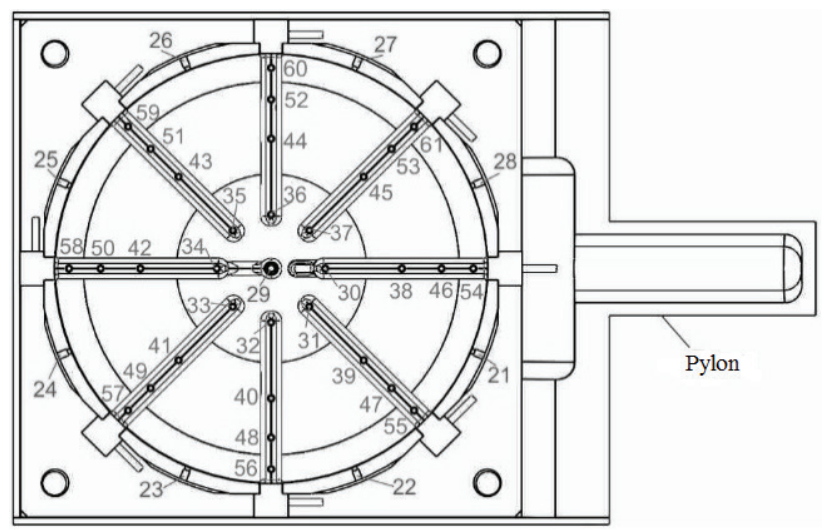

Figure 6. Diagram of static $(21-29)$ and total pressure receivers

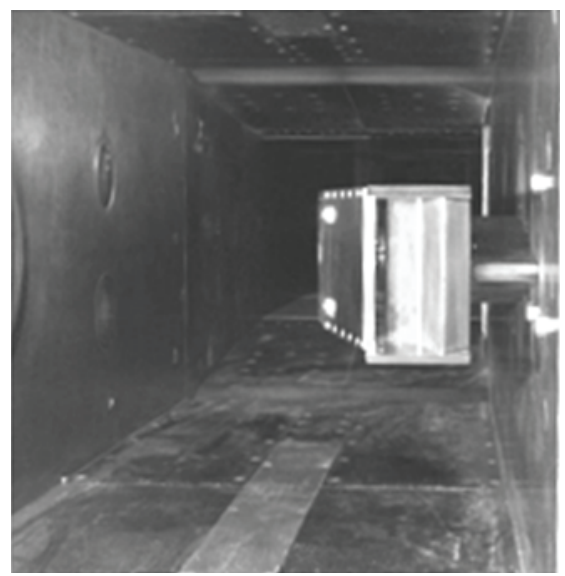

Figure 7. Ramjet's air intake PSM mounted in the tested part of the WT

The position of the valve (item 2, Figure 4) has been adjusted according to every intake configuration discretely via using several sets of spacing bushes of the different lengths (item 3, Figure 4).

The static pressure taps on the side cheek of the inlet diffuser are distributed in such a way that in the case of the rated operating mode of the air intake, the first two points (1 and 2) are located in an unperturbed flow (see Figure 5).

\section{Wind tunnel experiment for determining the supersonic ramjet air intake properties and the result analysis}

In the field of supersonic speeds, the discrete assignment of the flow velocity in WT is performed by means of shaped inserts in the working part of the WT (see Figure 8).

The Mach number and velocity pressure in the WT testing section are calculated from the static and total pressures measurements in the settling chamber of the WT. The absolute pressure values are determined by using the flow parameters measuring device (FPMD) of a lever type. According to Dubov and Maskaev 1983, the metrological characteristics of the FPMD comply with the requirements for standard pressure gauges of Category II.

The Mach number is determined by the ratio:

$$
M=\sqrt{5 \times\left[\left(\frac{\mathrm{p}_{\mathrm{t}}}{\mathrm{p}_{\mathrm{s}}}\right)^{\frac{2}{7}}-1\right]},
$$

where $p_{t}$ is the total pressure, and $p_{s}$ is the static pressure.

The measured velocity pressure is expressed as:

$$
\mathrm{q}=0.7 \times \mathrm{M}^{2} \times \mathrm{p}_{\mathrm{s}} .
$$

Reynolds number is determined by the ratio:

$$
\mathrm{Re}=0,07 \times 1 \times \mathrm{p}_{\mathrm{t} 1} \times \mathrm{M} / \mu \times \sqrt{\mathrm{T}_{01}} \times\left(1+0,2 \times \mathrm{M}^{2}\right)^{3},
$$

where $p_{t 1}$ - total pressure at prechamber;

$\mu=1,712 \times 10^{-6} \times(T / 273)^{0,75}$ - dynamic viscosity coefficient; $\mathrm{T}=\frac{T_{01}}{1+0,2 \times \mathrm{M}^{2}}-$ temperature at prechamber;

$\mathrm{T}_{01}$ - stagnation temperature, $l$ - characteristic length of WTT submodel.

Depending on the Mach number, the values of the Reynolds number and dynamic pressures in the WTT are listed in Table 2.

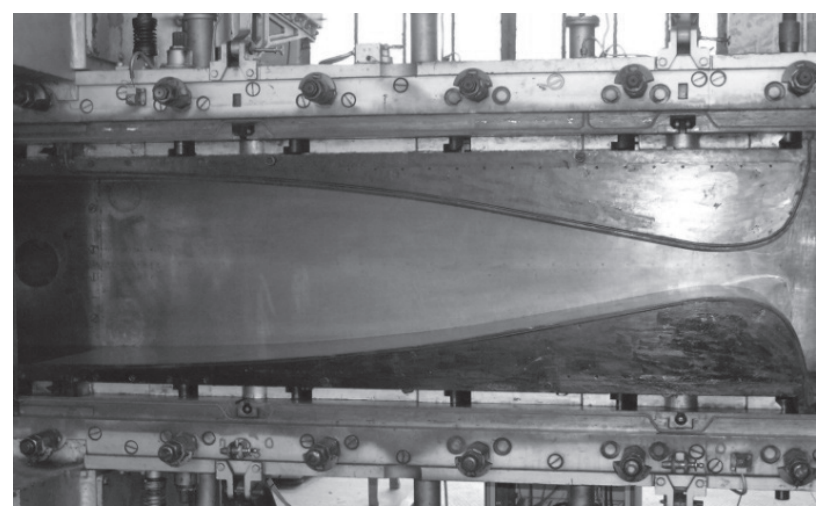

Figure 8. View of the WT nozzle inserts that helps maintain the Mach number $M=3$ 
Table 2. Mach number, Reynolds number and velocity pressure of experimental airflow

\begin{tabular}{|c|c|c|}
\hline$M$ & $R e$ & $q, \mathrm{~N} / \mathrm{m}^{2}$ \\
\hline 1.5 & $2.1 \times 10^{7}$ & 59000 \\
\hline 2.0 & $2.26 \times 10^{7}$ & 70000 \\
\hline 3.0 & $3.3 \times 10^{7}$ & 67000 \\
\hline
\end{tabular}

The flow parameters are corrected for the field coefficient obtained from the experimental studies of the static pressure field using a multi-point static pressure probe. The analysis of the determination errors of $M$ and $q(\mathrm{Pe}-$ tunin, 1986) shows that when using the FPMD of a lever type, the relative error does not exceed the values of $0.2 \%$ and of $0.25 \%$, respectively.

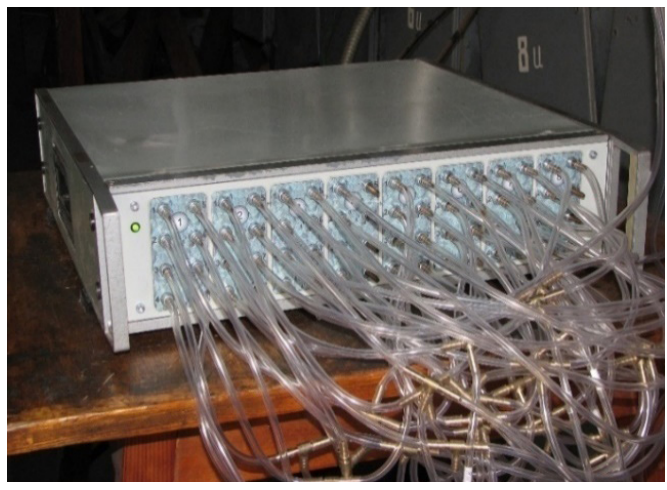

Figure 9. Measurement module of wind tunnel pressure
The limit of the absolute pressure measurement for a 64-channel computerized analogue-digital system for measuring pressure in WT (see Figure 9) is $250 \mathrm{kPa}$.

For each installation of external connectors, the pneumatic lines of the test ramjet air intake model (see Figure 10) has been checked for air-tightness using a pressure calibrator.

A comparison of digital simulation and wind tunnel test results at different time steps is shown in Figures 11-15. The flow in the air intake is characterized by a significant non-uniformity due to its separation mainly in the leeward area of the external braking wedge (see Figure 13).

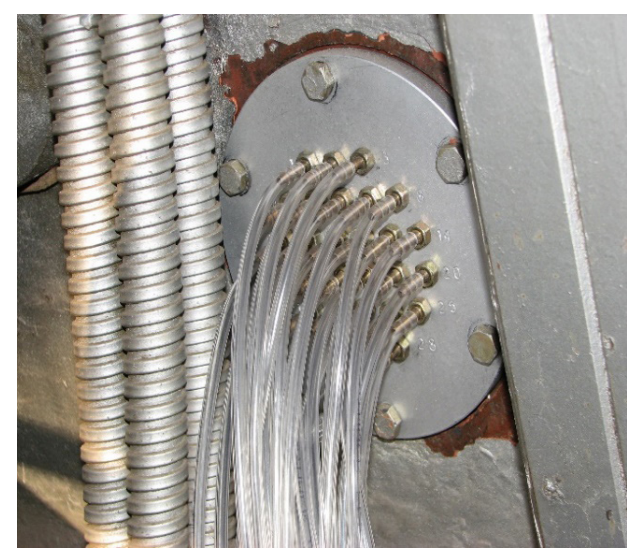

Figure 10. Hermitised pneumatic connectors of the physical submodel

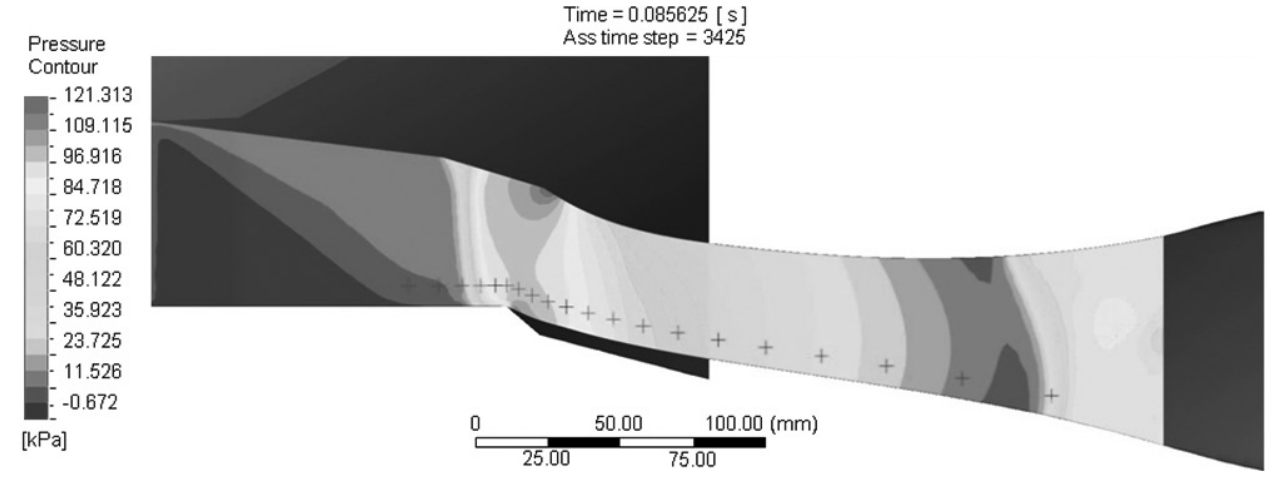

Figure 11. Static pressure distribution at the symmetry plane of the inlet diffuser

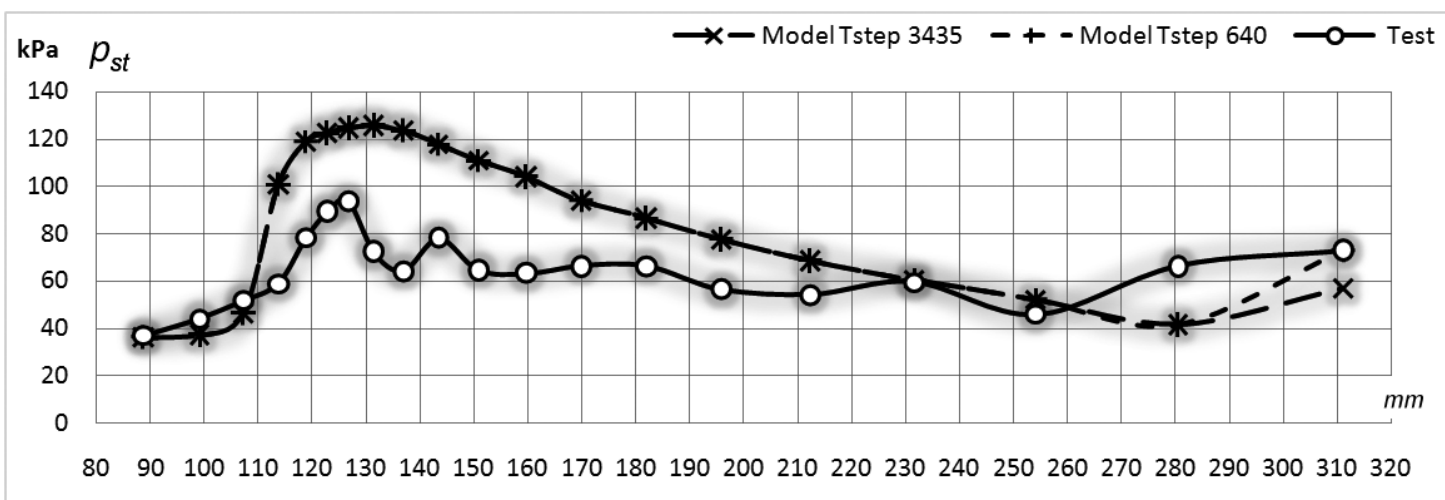

Figure 12. Static pressure distribution on the inlet diffuser' side surface (at the points of drainage according to Figure 5) 


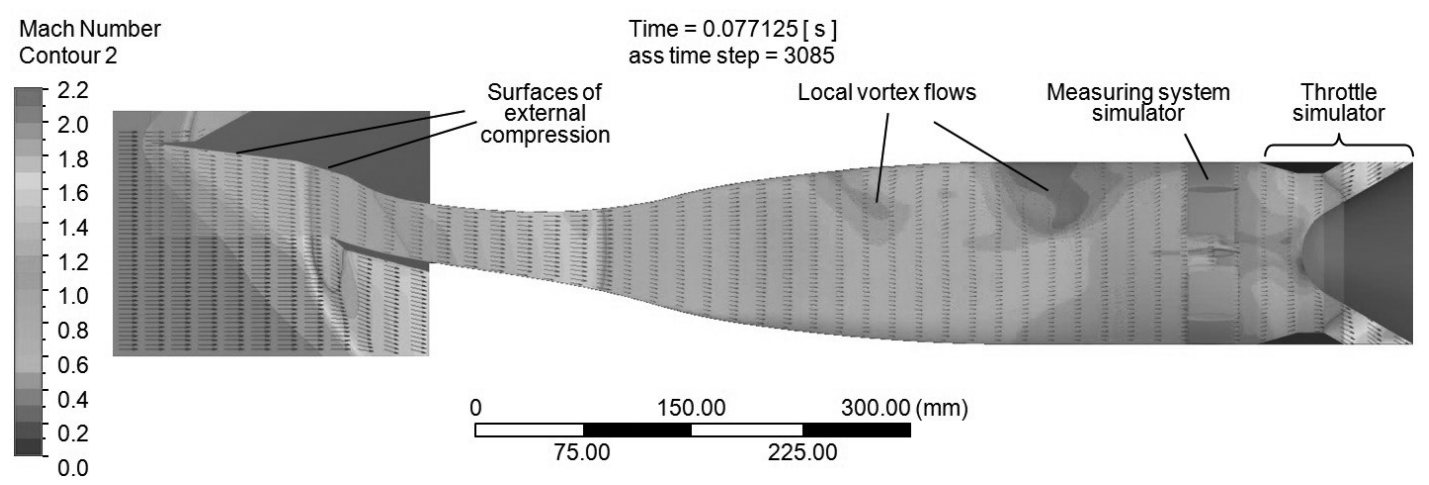

Figure 13. Field distribution of the instantaneous flow velocity in the symmetry plane

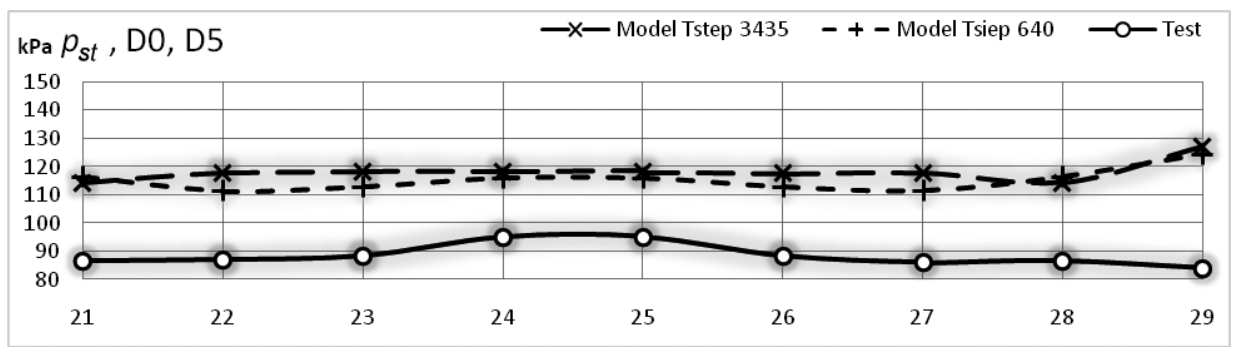

Figure 14. Field distribution of the instantaneous flow velocity in the symmetry plane
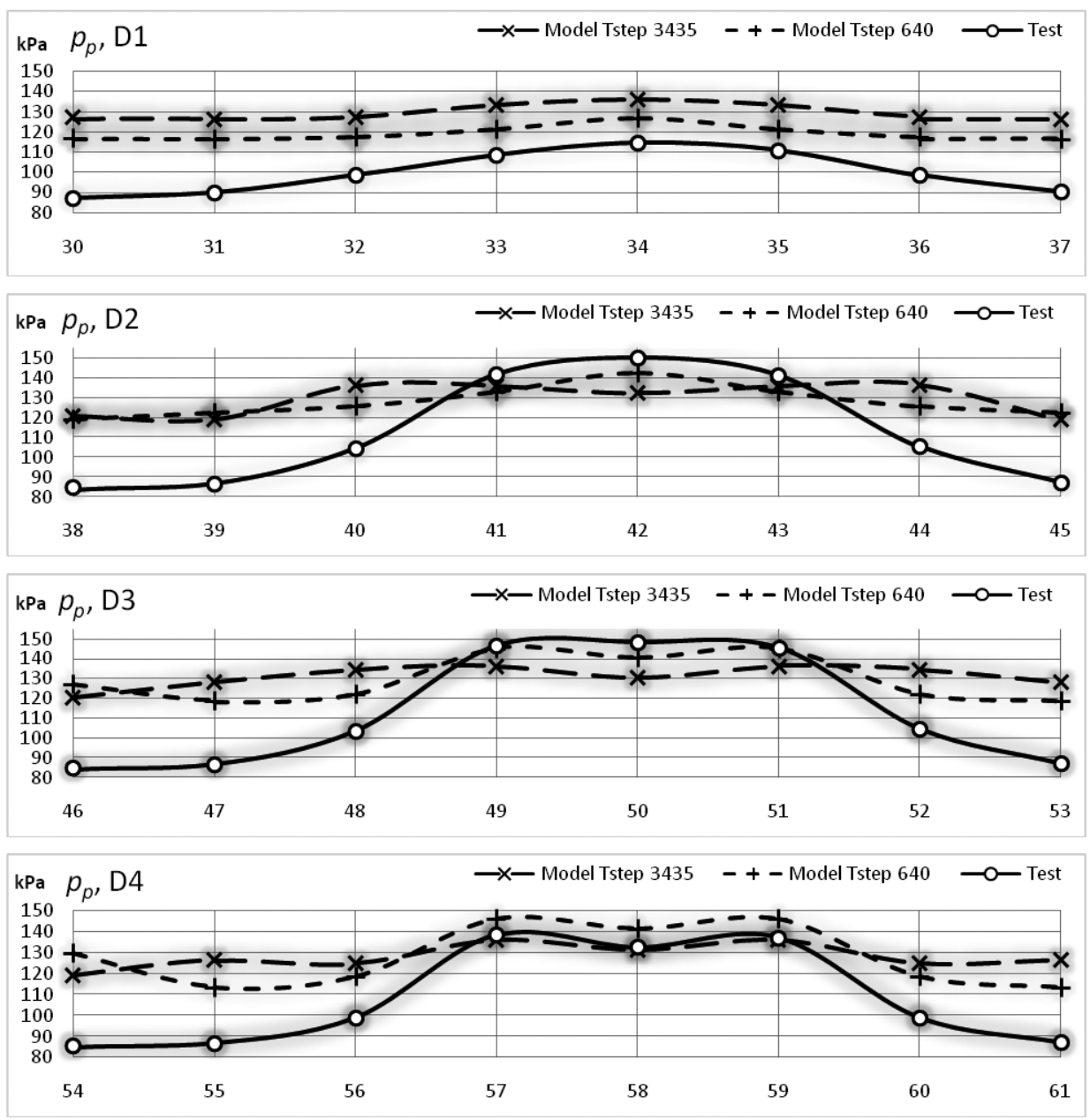

Figure 15. The measuring module total pressure circumferential distribution (at the drainage points according to Figure 6) 
As can be seen from the graphs in Figure 12, the calculated curves obtained by the Computational Fluid Dynamic simulation are geometrically correlated with the results of the WTT. However, there is a greater level of non-uniformity of the parameters obtained from WTT.

It is expected that the closest results of the circumferential pressures distribution, both $p_{s}$ and $p_{t}$, correspond to regions of the unseparated flow, namely the sector opposite to the compression wedge (in the vicinity of pressure heads with numbers $24,25,34,42,50,58$ according to Figure 6). See Table 3.

Table 3. Calculation error of flow parameters (\%)

\begin{tabular}{|c|c|c|c|}
\hline & & $\begin{array}{l}\text { The region of } \\
\text { unseparated flow }\end{array}$ & $\begin{array}{r}\text { The region of } \\
\text { separated flow }\end{array}$ \\
\hline D0 & $\begin{array}{c}\Delta p_{s} \\
\Delta p_{c m}\end{array}$ & - & +50 \\
\hline D1 & \multirow{4}{*}{$\begin{array}{c}\Delta p_{t} \\
\Delta p n\end{array}$} & $+10 \div+23$ & $+18 \div+44$ \\
\hline $\mathrm{D} 2$ & & $-0.04 \div-12$ & $+19 \div+40$ \\
\hline D3 & & $-0.01 \div-13$ & $+17 \div+49$ \\
\hline $\mathrm{D} 4$ & & $-0.01 \div+0.07$ & $+19 \div+52$ \\
\hline D5 & $\Delta p_{s}$ & +24 & $+34 \div+36$ \\
\hline
\end{tabular}

In addition, it should be noted that the results obtained in the course of WTT are consistent with the results obtained in the course of the other experiments carried out before the described one. For example, the qualitatively similar distributions of the static pressure over the air intake side surface and close to the sinusoidal distribution of total pressure over the inlet cross-section of the PS is noted in Air Intakes 1991. It is likely that more intense turbulent mixing of the flow in the CFD helps flatten the field of $p_{n}$ (see Figures 14,15) amid rising nonuniformity of a velocity field (Knight, 2003). This indicates the difference in the nature of the separated flow in the CFD and WTT and is regular for the initial phases of the CFD. As a result of the carried-out verification, the necessity of the tuning of digital models according to the WTT results has been revealed.

\section{Conclusions}

The classic techniques of aerodynamic designing have a number of key limitations that restrict the development of new high-speed ramjet air vehicles, including the following:

1. Recreation of ramjet workflow on scaled models is impossible due to non-scalability of the fuel-air mixture stoichiometric parameters.

2. In the WT with a small working section, the similarity of the Mach and Reynolds numbers in supersonic and subsonic portions of the duct cannot be achieved at the same time. Consequently, it is not possible to correctly determine the aerodynamic properties of the prototype ramjet by recalculating those for the scaled model using the similarity criteria described above.

3. Typically, wind tunnels cannot provide the airflow conditions required to test next-generation highspeed ramjet air vehicles.

The proposed approach to aerodynamic design allows to avoid all these shortcomings.

The main idea of the approach is to shift the emphasis of aerodynamic design from WTT to CFD simulations. WTT can be used for tuning and validation of the numerical model and prototype simulation. The airflow parameters and the geometry of a simulated prototype or WTT model are identical to those used in the CFD numerical model. This eliminates the need to satisfy the similarity criteria.

Using the same integrated numerical model for evaluating the integral gas-dynamic properties and tuning and adjusting the "ramjet - inlet" workflow according to the prototype flight modes complete the stage of advanced design of the prototype ramjet PS (see Figure 1), which precedes the physical implementation stage.

The described WTT is part of the R\&D program of integrated design of ramjet internal and external airflows for new-generation aircrafts. Performance of the integrated approach has been confirmed during studies of subsonic aircraft models (Kornev et al., 2018). This is just one example of many applications where the proposed approach to design can be used.

The proposed approach is promising for designing intricate aerodynamic air vehicle components.

It significantly decreases development cost by reducing the scope of vulnerable WTT in the overall design cycle.

\section{Author contributions}

AS and DK conceived the study and were responsible for funding. VY and SS were responsible for the physical model and experiment designing. VY was responsible for WTT data collection. SS was responsible for CFD simulations. AK was responsible for obtained data analysis, comparison, and interpretation. AK and SS formulated the new approach to gas-dynamic designing and were responsible for the writing of the article.

\section{Disclosure statement}

Authors have no competing interests from other parties.

\section{References}

Akman, O. (2014). Subsonic-transonic submerged intake design for a cruise missile [Diss. master of science in aerospace engineering] (99 p.). Ankara. https://docplayer.net/49267931Subsonic-transonic-submerged-intake-design-for-a-cruisemissile.html 
Bedretdinov, I. (2005). The strike and reconnaissance aircraft T-4 (Volume 2). Series "The Golden Fund of Domestic Aviation" (248 p.). "Bedretdinov and Co. Publishing Group" LLC.

Davis, M. W., Jr., Hale, A. A., Klepper, J., Dubreus, T., \& Cousins, W. T. (2010, 4-7 January). Demonstration of an Integrated Test and Evaluation (IT\&E) process for airframe-propulsion systems as applied to a current weapon system program. In 48th AIAA Aerospace Sciences Meeting Including the New Horizons Forum and Aerospace Exposition, AIAA Paper 2010 1039. Orlando, Florida.

https://arc.aiaa.org/doi/10.2514/6.2010-1039

Druzhinin, E. A., Chmovzh, V. V., \& Kornev, A. V. (2011). Application of aerodynamic design methods while life cycle implementation for advanced aeronotical engineering development. Science magazine "Weapons systems and military equipment", 4(28), 48-57.

Dubov, B. S., \& Maskaev, V. K. (1983). Metrological support of instrumentation for measuring pressure in wind tunnels. In Proceedings of TsAGI, TsAGI, 227, 40-52. Moscow. http://www.hups. mil.gov.ua/periodic-app/article/1906/soivt_2011_4_12.pdf

DTIC. (1991). Air intakes for high speed vehicles.In Report documentation page AGARD-AR-270. Neuilly sur Seine: AGARD NATO, sept. 1991 (pp. 183-211). https://archive.org/details/ DTIC_ADA248270/page/n61

Holland, S. D. (1991). Computational and experimental investigation of a Three-Dimensional Hypersonic Scramjet Inlet Flow Field (676 p.) [ $\mathrm{PhD}$ thesis in aerospace engineering, hypersonic aerodynamics. North Carolina State University].

Jirásek, A. (2007, 20-21 June). Example of integrated CFD and experimental studies: design of flow control in the FOIEIC-01 Inlet. In 3rd International Symposium on Integrating CFD and Experiments in Aerodynamics. U.S. Air Force Academy. http://citeseerx.ist.psu.edu/viewdoc/download?doi=10.1 $.1 .556 .6504 \&$ rep $=$ rep $1 \&$ type $=$ pdf

Karpov, E. V., \& Novogorodtsev, E. V. (2014a, 22-24 April). Calculation of flow in trapezoidal air intake with the curvilinear channel. In Collected theses of the reports of the scientific-practical conference "Innovations in Aviation and Cosmonautics-2014” (pp. 51-52). MAI. https://docplayer. ru/36051430-Innovacii-v-aviacii-i-kosmonavtike-2014.html

Karpov, E. V., \& Novogorodtsev, E. V. (2014b, 17-21 November). Numerical investigation of the boundary-layer suction effect on capability of trapezoidal air inlet. In Collected theses of the reports of the 13th International Conference "Aviation and Cosmonautics-2014" (pp. 64-65). MAI. http://files.mai. ru/site/conf/aik/2014/Abstracts.pdf

Karpova, V. E., \& Meshennikov, P. A. (2014, 22-24 April). Computational research of a frontal air intake device for smallsized high-speed aircraft. In Collected theses of the reports of the scientific-practical conference "Innovations in Aviation and Cosmonautics-2014" (p. 30). MAI. https://docplayer. ru/36051430-Innovacii-v-aviacii-i-kosmonavtike-2014.html

Knight, D. (2003, 3 June). Data driven design optimization methodology a dynamic data driven application system. In
International Conference on Computational Science, Paper (p. 29). ICCS03. http://citeseerx.ist.psu.edu/viewdoc/downlo ad?doi=10.1.1.121.1409\&rep=rep1\&type $=$ pdf

Kornev, A. V., \& Boychuk, I. P. (2017). Complex approach to aerodynamic design of inlet ducts with submerged vortexfree air intakes. Bulletin of the Samara University. Aerospace Technics, Technologies and Mechanical Engineering, 16(2), 47-59. Samara National Research University named after academician S.P. Korolev. http://journals.ssau.ru/index.php/ vestnik/article/view/5118

Kornev, A. V., Sereda, V. A., \& Migalin, K. V. (2018). Aerodynamic design method of integrated aircraft with submerged intake devices and power plant included into airframe carrying system. Russian Aeronautics, 61(1), 17-25. https://link. springer.com/article/10.3103\%2FS1068799818010038

Petunin, A. N. (1986). Errors of measurement of the main parameters of subsonic and supersonic flow with various combinations of partial errors of pressure measurement. In Proceedings of TsAGI, 1024, 39-76. TsAGI.

Rademakers, R., Bindl, S., Brehm, S., Muth, B., \& Niehuis, R. (2013). Investigation of flow distortion in an integrated inlet of a jet engine. In 62nd German Aerospace Congress, Conference Paper D-85577. Stuttgart, September 2013. https://www. researchgate.net/publication/257014200_Investigation_of_ Flow_Distortion_in_an_Integrated_Inlet_of_a_Jet_Engine

\section{Notations}

\section{Variables and functions}

$H$ - altitude $[\mathrm{m}]$;

$M$ - Mach number [-];

Re - Reynolds number [-];

$p_{s}$ - static pressure $[\mathrm{Pa}]$;

$p_{t}-$ total pressure $[\mathrm{Pa}]$;

$q$-dynamic pressure $[\mathrm{Pa}]$.

\section{Abbreviations}

WT - wind tunnel;

WTT - wind tunnel tests;

PS - propulsion system;

CFD - computational fluid dynamic;

DM - digital model;

ISA - International standard atmosphere;

DSM - digital submodel;

PSM - physical submodel;

FPMD - flow parameters measuring device. 